\title{
Impact of preventive measures on improving functional state of persons with chronic obstructive pulmonary disease in industrial city conditions
}

\author{
Elena Maksimikhina ${ }^{1, *}$ \\ ${ }^{1}$ Cherepovets State University, Cherepovets, Russia
}

\begin{abstract}
The article presents data on the dynamics of the incidence of chronic obstructive pulmonary disease in the adult population of Cherepovets. 23 people aged $42-74$ years were examined. In the course of the study, preventive measures were proposed to reduce the increase in morbidity and improve the quality of life of people with COPD. To assess the functional state of individuals with chronic obstructive pulmonary disease, a 6-minute stress test (6-MCT) was used, and the degree of dyspnea was assessed using the Borg scale. In the process of implementing preventive measures, their effectiveness and significant improvement in the functional state of persons with chronic obstructive pulmonary disease are shown.
\end{abstract}

\section{Introduction}

In the total number of recorded cases of diseases, respiratory diseases are distinguished, which include acute respiratory infections of the upper respiratory tract, influenza and pneumonia, other acute respiratory infections of the lower respiratory tract, chronic diseases of the lower respiratory tract, as well as other diseases. Their share in the total incidence is gradually, albeit with some fluctuations, declining, reaching about 25\% in 2016-2017, compared to $28 \%$ in $2000,30 \%$ in 1995 and $36 \%$ in 1990 [9].

Among respiratory diseases, one of the most common diseases in which mortality continues to increase not only in Russia, but also around the world remains COPD. According to the US National Institute of Health, COPD mortality rates in the age groups of people over 60 ranks $4-5$, i.e.are among the main causes in the US mortality structure. In other European countries, deaths from COPD range from 2.3 (Greece) to 41.4 (Hungary) per 100,000 population [1]. For Russia, where there are high rates of smoking population, a fairly high number of people with respiratory diseases, a large existence of industrial cities, a cold weather for 4-5 months a year, COPD is of particular relevance. According to the Ministry of Health of the Russian Federation, the prevalence of COPD is $1.7 \%$ (2.4 million patients), while the actual number of such patients can exceed 11 million [6.7]. N.S. Semenova, N.M. Balabina in their studies confirm the significant influence of multiple

\footnotetext{
*Corresponding author: elena_maksimihina@mail.ru
} 
factors on COPD formation, dividing them into exogenous and endogenous. Cigarette smoking is the most studied among them, but not the only factor instigating the development of the disease [5].

A number of studies note that a long, four or more years, living in areas with high industrial air pollution with no rest in suburban areas with a relatively favorable environmental situation is a risk factor for the development of respiratory system pathology [2].

A.G. Chuchalin, I.V. Leshchenko, S.I. Ovcharenko, E.I. Shmelev draw attention to the fact that COPD is a disease that can be prevented and treated. COPD preventing maesures are an integral part of overall efforts to prevent chronic diseases. They aim to reduce cases of exacerbations and complications of COPD and clinical symptomatic relief of the disease. They also affect the change in the functional state of persons with COPD, the improvement of physical activity tolerance, and the improvement in the quality of life of persons with this diagnosis $[3,4,6,8]$.

On the example of one of the industrial cities of the North-West of Russia (Cherepovets), we compared the indicators of the dynamics of the total incidence of COPD over three years, based on the analysis of statistical data obtained at the Cherepovets Office of the Organization of Health-care Protection of the Department of Public Health of the Vologda Region.

Having analyzed the data obtained, it can be stated that in the dynamics of the threeyear period, the number of residents with a COPD diagnosis increased from 1011 in 2016 to 1092 residents in 2018 . The growth rate was $8 \%$. Also, the number of residents on outpatient observation doubled from 263 people in 2016 to 551 people in 2018 . The growth rate was $109.5 \%$. One of the factors contributing to this situation can be considered an unfavorable state of ecology in Cherepovets due to the large number of industrial enterprises. The city of Cherepovets is the largest industrial center in the North-West of Russia. It ranks 9th among the largest industrial centers in Russia. The main industrial potential is concentrated in the metallurgical and chemical industries. This can cause high level of pollution of the atmospheric air and other natural environment, which also contributes to a significant increase in the number of residents with COPD.

We also compared the rates of primary COPD incidence of the adult population between 2016 and 2018. The primary incidence according to the established diagnosis of COPD of the adult population in Cherepovets according to outpatient data increased from 67 residents in 2016 to 213 residents in 2018 . The growth rate was $217.9 \%$. In our opinion, new approaches are needed to assess and prevent risk factors for the occurrence of this disease. Such measures will reduce the increase in morbidity and mortality from chronic obstructive pulmonary diseases and improve the quality of life of people with COPD.

\section{Research materials and methods}

The aim of this study was to identify the impact of using preventive measures on the dynamics of functional state indicators of persons with chronic obstructive pulmonary disease of the adult population of Cherepovets.

The study was conducted on the basis of the day-time hospital of BUZ VO Cherepovets City Hospital. The study involved 23 people, with a recorded diagnosis of chronic obstructive pulmonary disease, 7 of them $(30.4 \%)$ were women, $16(69.6 \%)$ were men. The age of patients is from 42 to 74 years. The following methods were used to assess the functional state indices of the subjects:

1. 6 minute load test.

2. Estimate of shortness of breath using the Borg scale. 
For 21 days, all patients were in a day-time hospital. Several seminars were held during this period:

"COPD is a disease of smokers";

" Risk factors of the development of COPD"

"Ways of preventing COPD"

"Tobacco smoking prevention tools and methods."

One of the mandatory preventive measures was the inclusion of therapeutic and respiratory gymnastics in the lifestyle of persons with COPD. Medical gymnastics for COPD patients was carried out daily twice a day, lasting 20 minutes; Physical therapy classes were combined with medication, which was regulated by a doctor; an important requirement was a significant reduction in tobacco consumption. Also, 2 group classes were held to teach patients the elements of respiratory gymnastics. Over the next 6 months, patients with a diagnosis of COPD were asked to perform complexes of therapeutic and respiratory gymnastics independently. Exercises are recommended to be performed five times a day, reducing or increasing the number of repetitions depending on well-being. At the end of each of them, it is recommended to measure the HR.

\section{Results of the study}

In phase I of the pilot study, we conducted a questionnaire survey among patients with an early established diagnosis of COPD, including questions that can be divided into the following categories:

1. Demographic indicators (sex, age, profession).

2. Data from the history of the disease (features of the clinical course of COPD).

3. Socio-economic data (presence/absence of disability).

4. State of health at the time of survey.

5. Attitude to smoking.

The aim of the questionnaire survey was to identify how they experience the disease and how much the diagnosis of COPD affects the quality of life of the adult population.

During the questionnaire survey 19 patients (82.6\%) noted that they are or were employees of industrial enterprises. $86.9 \%$ of respondents were urban residents, $13.1 \%$ of respondents were rural residents. Of the study sample, $30.4 \%$ had a third disability group and $8.7 \%$ a second disability group.

All respondents noted that from the appearance of the first symptoms to the recorded diagnosis $7.92 \pm 5.8$ years passed. Among the main symptoms, patients note an increase in cough, an increase in the amount of sputum, a change in its color and shortness of breath. The majority of respondents $82.6 \%$ noted that the main symptom for seeing a doctor was an increase in shortness of breath.

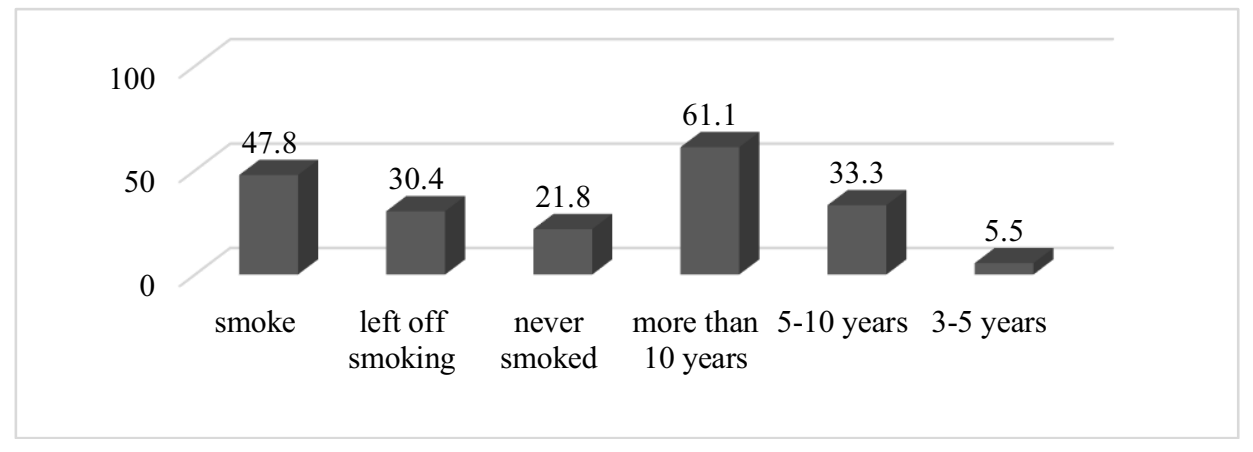

Fig. 1. Assessment of tobacco dependence degree of the adult population of Cherepovets. 
Figure 1 clearly shows that $1 / 2$ respondents have a high degree of tobacco dependence, $30.4 \%$ quit smoking, and only $21.8 \%$ have never smoked. Smoking experience of more than 10 years among smokers and quitters was identified in $11(61.1 \%)$ survey participants, $6(33.3 \%)$ speak of 5-10 years of smoking, $1(5.5 \%)$ - 3-5 years.

$65.2 \%$ of patients experienced breathing difficulties while walking, $26.1 \%$ responded that they experienced minor difficulties, $8.7 \%$ did not experience difficulties during physical exercises.

After 6 months, we conducted a control phase of a pilot study, the purpose of which was to test the effectiveness of preventive measures for the dynamics of functional state indicators for persons with chronic obstructive pulmonary disease. We assessed the change in functional state of individuals with COPD in dynamics.

The analysis of the results showed that the preventive measures proposed by us turned out to be effective for all indicators of functional state among the subjects of the examined group.

Table 1. Dynamics of functional state level during the study ( 6 minute load test, $n=20), \%$.

\begin{tabular}{|c|c|c|c|}
\hline No. P/N & Functional state level & I testing & II testing \\
\hline 1 & Above the norm & - & 50 \\
\hline 2 & Norm & 25 & 30 \\
\hline 3 & Below the norm & 40 & 15 \\
\hline 4 & Very low level & 35 & 5 \\
\hline
\end{tabular}

As can be seen from the data presented in Table 1, it can be clearly seen that in most subjects the level of daily activity has changed significantly and is within the normal range in $85 \%$, only 2 people - $10 \%$ have an activity level below normal and 1 person - 5\% remained at a very low level, which means low physical activity in everyday life.

Table 2. Dynamics of functional state level during the study (level of shortness of breath on the Borg scale. $n=20), \%$.

\begin{tabular}{|c|c|c|c|c|}
\hline \multirow[b]{2}{*}{$\begin{array}{c}\text { Severity of } \\
\text { shortness of } \\
\text { breath }\end{array}$} & \multicolumn{2}{|c|}{ I testing } & \multicolumn{2}{|c|}{ II testing } \\
\hline & $\begin{array}{l}\text { Shortness of } \\
\text { breath on the } \\
\text { Borg scale } \\
\text { before the test }\end{array}$ & $\begin{array}{c}\text { Shortness of } \\
\text { breath on the } \\
\text { Borg scale after } \\
\text { the test }\end{array}$ & $\begin{array}{l}\text { Shortness of } \\
\text { breath on the } \\
\text { Borg scale } \\
\text { before the test }\end{array}$ & $\begin{array}{c}\text { Shortness of } \\
\text { breath on the } \\
\text { Borg scale after } \\
\text { the test }\end{array}$ \\
\hline light & 95 & 5 & 95 & 35 \\
\hline moderate & 5 & 50 & 5 & 60 \\
\hline heavy & - & 45 & - & 5 \\
\hline
\end{tabular}

According to indicators assessing the state of the respiratory system in the subjects during the physical exercise, significant positive dynamics are also noted. Thus only $10 \%$ of the subjects at the end of our study show a severe degree of shortness of breath during physical exercise, while at the beginning this indicator was noted in $45 \%$ of the subjects. Most people note only mild (35\%) and moderate $(55 \%)$ shortness of breath by the end of the study. For a more accurate comparison of the data obtained during the experimental study, the method of connected samples was used, estimated using Student's t-criterion and Wilcoxon's t-criterion. The results are shown in Table 3-4.

Table 3. Calculation of validity of differences in study results to Student's t-test (6-minute load test).

\begin{tabular}{|c|c|c|c|c|c|}
\hline examinee & $\begin{array}{c}\text { I testing } \\
(\mathbf{X} \pm \mathbf{m})\end{array}$ & $\begin{array}{c}\text { II testing } \\
(\mathbf{X} \pm \mathbf{m})\end{array}$ & $\mathbf{t}_{\text {Эмп }}$ & $\mathbf{t}_{\mathbf{K p}}$ & $\mathbf{p}$ \\
\hline men & $484.8 \pm 122.7$ & $515.9 \pm 122.4$ & 12.4 & 3.05 & $\leq 0.05$ \\
\hline women & $469.3 \pm 122.6$ & $494.6 \pm 110.6$ & 4 & 3.71 & $\leq 0.05$ \\
\hline
\end{tabular}


The obtained empirical value, for both men tEmp (12.4) and women tEmp (4), is in the zone of significance. Therefore, the preventive measures we used had a positive effect on the functional state of individuals with COPD.

Table 4. Calculation of validity of differences in study results according to the Wilcoxon T-criterion (level of shortness of breath on the Borg scale after the test)

\begin{tabular}{|c|c|c|c|c|c|}
\hline examinee & $\begin{array}{c}\text { I testing } \\
(\mathbf{X} \pm \mathbf{m})\end{array}$ & II testing $(\mathbf{X} \pm \mathbf{m})$ & $\mathbf{t}_{\text {Эмп }}$ & $\mathbf{t}_{\text {Kp }}$ & $\mathbf{p}$ \\
\hline men & $4.5 \pm 0.8$ & $3.3 \pm 1.1$ & 3 & 12 & $\leq 0.05$ \\
\hline women & $3.7 \pm 1.4$ & $2.6 \pm 1.1$ & 1 & 0 & $\geq 0.05$ \\
\hline
\end{tabular}

Based on the calculations of the validity of differences in results according to the Wilcoxon t-criterion when assessing the functional state of the respiratory system (when measuring shortness of breath using the Borg scale after a 6-minute load test) in men, Temp $>\operatorname{Tkr}(0.05)$ is in the zone of significance, in women, the obtained empirical value of $t$ $(\mathrm{tEmp}=1)$ is in the zone of uncertainty, respectively. This can be explained by the fact that the sample size in women $(\mathrm{n}=7)$ turned out to be small and the study period was short. We can assume that with the increase in the period of the experimental study, the increase in the number of subjects, the results may be more pronounced and significant.

\section{Discussion and conclusion}

After conducting this study, it can be stated that a significant result in reducing the incidence and mortality from COPD can be achieved only by a comprehensive effect on the main factors affecting the development of this disease. The main risk factors for COPD include smoking, genetically induced factors, frequent respiratory infections, as well as occupational activities associated with the presence of harmful labour conditions, and others. On the issue of prevention of COPD, many authors agree on the separation of measures aimed at the primary and secondary prevention of the disease.

Analyzing the obtained data, we can conclude that chronic obstructive pulmonary disease is of particular relevance among the adult population of Cherepovets. Presence of industrial enterprises, cold climate, high prevalence of smoking, high incidence of respiratory infections - these factors contribute to the development of the disease. Regular preventive measures will have a significant positive impact on the health of the working population and the extension of working capacity.

\section{References}

1. S.A. Babanov, P.V. Gajlis, Therapist 4, 59-67 (2010)

2. M.G. Gambarjan, N.A. Didkovskij, A.M. Kalinina et al., Pulmonology 3, 72-76 (2006)

3. I.V. Leshhenko, Jesaulova N.A. Pulmonology 30, 101-109 (2005)

4. S.I. Ovcharenko, Pulmonology 6, 69-72 (2011)

5. N.S. Semenova, N.M. Balabina, Siberian Medical Journal 5, 8-10 (2007)

6. A.G. Chuchalin, S.N. Avdeev, Z.R. Ajsanov et al., Pulmonology 3, 15-61 (2014)

7. A.G. Chuchalin, Pulmonology (GEOTAR-Media, M., 2009)

8. E.I. Shmelev, Atmosphere. Pulmonology and allergology 4, 51-54 (2011)

9. E.M. Shherbakova, Demoscope Weekly, 807-808 (2019) 